To conclude, if we agree that, for the majority of paraplegics, work is indispensable for physical and psychological reasons, we must also stress that health conditions and fatigability should be taken into account. Time and physical facilities should be left also for social life, leisure and nursing.

Occupational guidance and training have to be considered very early during the paraplegic's stay at the rehabilitation centre and the question of pension quickly cleared up. Multiple possibilities of work should be provided through the creation of occupational training-centres, protected workshops, and hostels (especially for tetraplegics). Part-time work and adjustment of working arrangements should be made easier.

Finally, social conditions and adjustment would be greatly improved if it were possible to grant to every patient an easily accessible dwelling, an adapted car, a second wheelchair for work, and if it were assured that neither the allowance for the help of an attendant nor the pension could ever be curtailed.

\title{
RESETTLEMENT PROBLEMS OF PARAPLEGIC MINEWORKERS
}

\author{
By A. G. Hardy, M.B.E., M.A., F.R.C.S. \\ Spinal Injuries Unit, Lodge Moor Hospital, Sheffield
}

THIs paper concerns a review of some of the principal problems of resettlement of paraplegic mineworkers during the period of the past Io years. All the cases have been patients at the Spinal Injuries Unit, Lodge Moor Hospital, Sheffield. All were early admissions within 6 to 72 hours of injury and the majority came from the coal-mines of either the Yorkshire North Eastern or East Midlands Division of the National Coal Board. A few cases came from Northumberland and Durham, the Cumberland and West Lancashire Divisions. It will be noted that these coalbearing areas surround Sheffield, which lies at the centre of the geographical area; and apart from the Cumberland and Durham groups all the mines are within 50 miles of the Unit, which thus obviates major difficulties in transportation.

Out of a total of 396 acute admissions, 127 came from mining accidents. It is interesting to compare the pattern of admissions over the Io-year period (fig. I and table I).

It will be noted that whereas the number of mineworkers varies within a fairly constant range, those cases of spinal injury from other causes show a steady increase. This is particularly noticeable in injuries due to falls and those due to road traffic accidents (R.T.A.). Nevertheless, injuries from mining accidents still account for 32 per cent. of all primary admissions at the Sheffield Spinal Injuries Unit. This trend is also shown in the incidence of admissions when reviewed as levels of injury (fig. 2 and table II). The steady rise in cervical injuries becomes clearly apparent.

In I 946 Nicoll reported that there were II 4 cases per annum per 100,000 mineworkers. The incidence in the period I954-63 must be very much the same. Nicoll reported that there was an early death rate of 30 per cent. within a period of three weeks and a death rate of 57 per cent. in the next two years. The comparative figures for 1954 to 1963 are less than I per cent. and 2 per cent. respectively. The duration of hospital in-patient treatment averages less than six months 


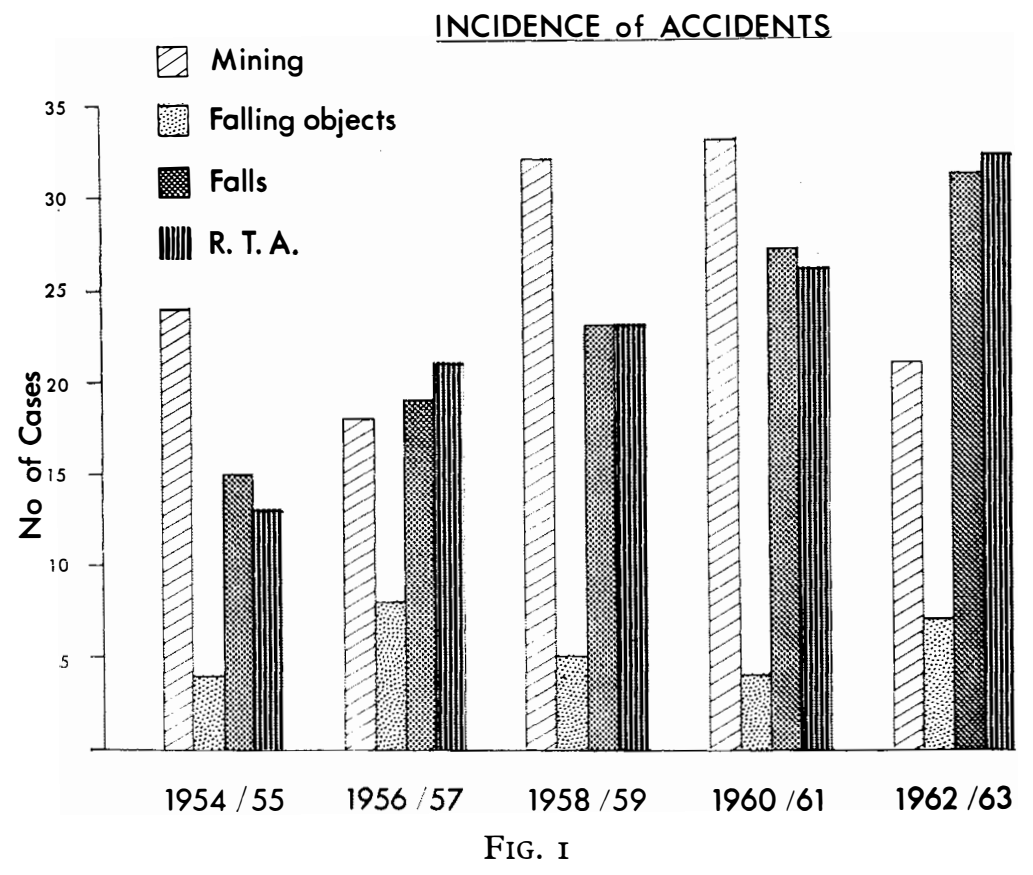

TABLE I

Incidence of Accidents

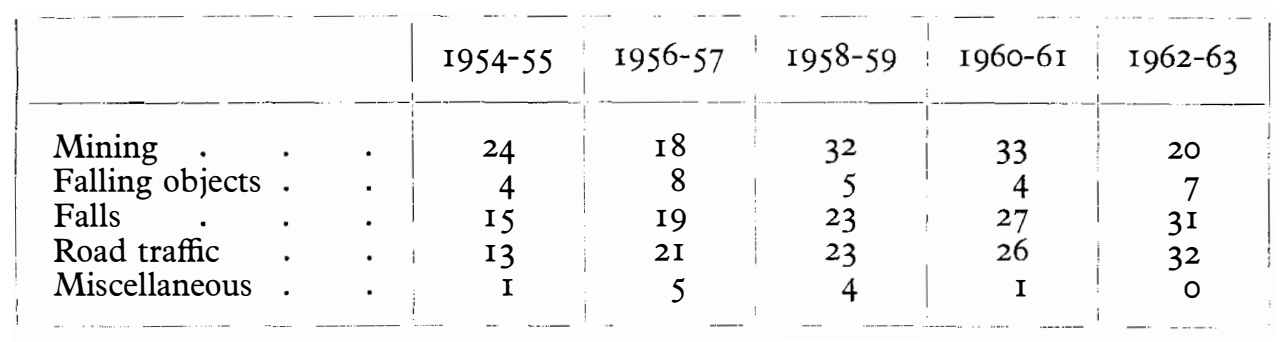

and with the establishment of an efficient medico-social service as part of the Coal Industry Social Welfare Organisation it has been possible to anticipate and meet the demands of any given disability in regard to the special needs for its care at home.

The degree of personal independence bears a close relationship to the severity of the disability which in turn is related to the level and degree of spinal cord damage. Nevertheless, the extent to which any one patient can compensate for his disability also depends on other factors such as age and family status and on what he has been taught of the ways and means of overcoming his handicaps. Also of paramount importance is the manner in which his domestic surroundings have been adapted to meet the particular needs of each disability.

These features will now be considered separately. 


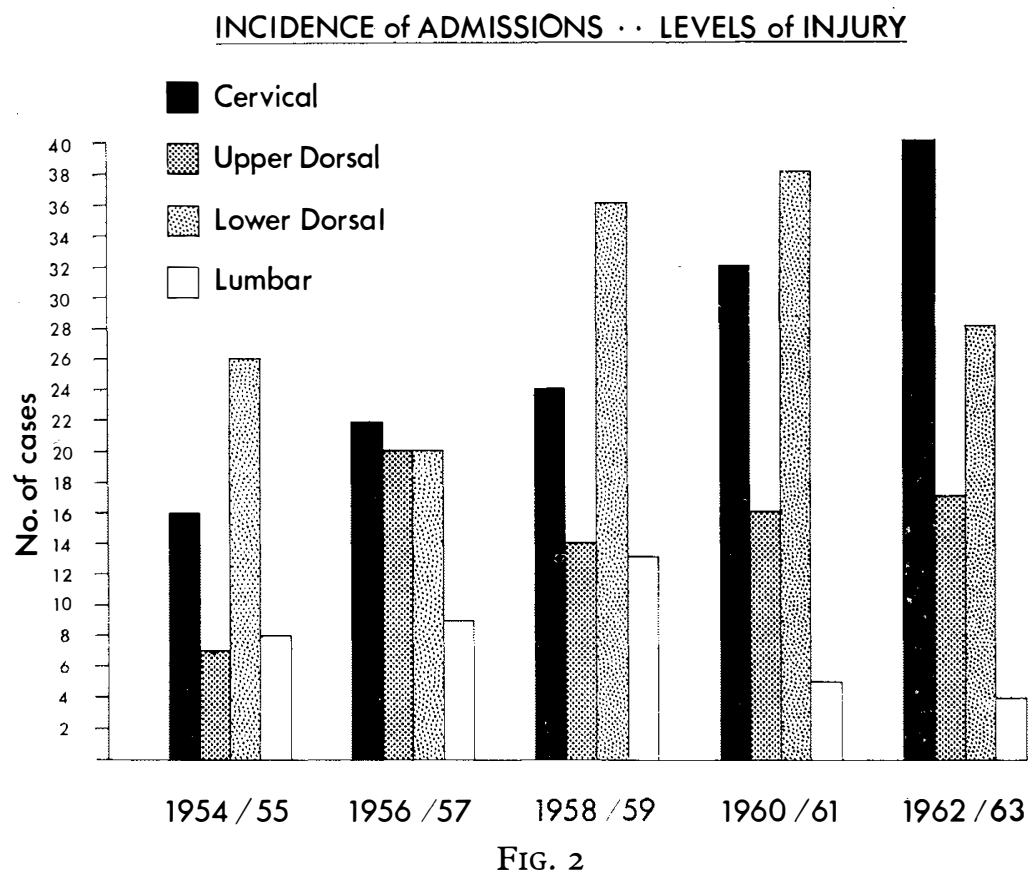

TABLE II

Incidence of Admissions

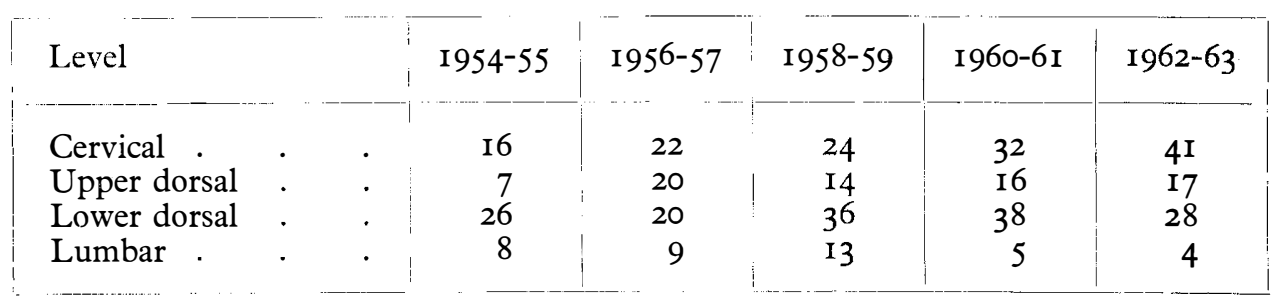

\section{AGE-GROUPS}

The age-groups of paraplegic mineworkers have altered in the past to years (table III). It will be seen from the table that in the period 1944-53 the predominant group was the youngest. In the period $1954-63$ the incidence moved to the older age-groups and 72 per cent. of them occurred in the 3 rd, 4 th and 5 th decades of life. This has special significance in regard to subsequent attitudes to the way of life and desire for re-employment as a disabled person.

\section{TYPE OF INJURY}

There were 127 mining accidents producing spinal cord injury, the location of which was in the neck in 12 cases, in the upper dorsal spine in five, in the lower 
dorsal spine in 85 and in the lumbar spine in 25 . This is a constant feature in mining accidents, where the majority of incidents are due to falls of roof.

The neck injuries were mainly hyperextension in type but all the other injuries were due to flexion violence. It will be noted that a little more than half of the cases had a complete paralysis below the level of the cord injury (table IV). This is of significance when budgeting for the aids for the disabled and similarly so when considering the need for housing alteration. Only three men required full custodial care.

TABLE III

Age-groups (Mining)

\begin{tabular}{|c|c|c|c|}
\hline Age-group & I $944-53$ & I95 & $54-63$ \\
\hline $\begin{array}{l}\text { I } 8-30 \\
3 I-40 \\
4 I-50 \\
5 I-60 \\
\text { Over 60 }\end{array}$ & $\begin{array}{rc}\text { No. } & 0 \\
52 & (44 \%) \\
38 & (32 \%) \\
\text { I8 } & (15 \%) \\
8 & (7 \%) \\
2 & (2 \%) \\
\text { I I } 8 & \end{array}$ & \begin{tabular}{|c|} 
No. \\
33 \\
44 \\
$3 \mathrm{I}$ \\
$\mathrm{I} 6$ \\
3 \\
$-\mathrm{I} 27$ \\
\end{tabular} & $\begin{array}{c}\% \% \\
(26 \%) \\
(35 \%) \\
(24 \%) \\
(13 \%) \\
(2 \%)\end{array}$ \\
\hline
\end{tabular}

TABLE IV

Level and Types of Paralysis

I954 to I963

\begin{tabular}{|c|c|c|c|c|}
\hline Level & & $\begin{array}{c}\text { Partial } \\
\text { Paralysis }\end{array}$ & $\begin{array}{l}\text { Complete } \\
\text { Paralysis }\end{array}$ & $\begin{array}{l}\text { Total } \\
\text { Cases }\end{array}$ \\
\hline Cervical & . & IO & 2 & I 2 \\
\hline Upper dorsal & . & 2 & 3 & 5 \\
\hline Lower dorsal & . & 25 & 60 & 85 \\
\hline Lumbar . & . & 24 & I & 25 \\
\hline & & $6 \mathrm{r}$ & 66 & 127 \\
\hline
\end{tabular}

\section{HOUSING}

Home features requiring attention in the majority of cases included the following:

I. Downstairs living and sleeping accommodation.

2. Width of doorways and passages.

3. The incidence of steps and stairs.

4. The availability of toilet and bathing facilities with a hot-water system.

5. Space for accommodation for an invalid tricycle or car. 
6. The need for gadgets such as wallbars, overhead grips, handrails and accessible switches.

The need for attention to the home circumstances must receive early attention. It is our practice to have the patient's home visited by the almoner as soon as it is possible to make a reasonable assessment of the likely residual disability. The decision in the first instance is simply one of three things: adequate, inadequate but adaptable, or inadequate and unadaptable. Even the best of normal home circumstances requires slight modification for the paraplegic patient. The general situation and the difficulties of management are observed when each patient is sent on a trial period at his home during the latter part of his period of hospital rehabilitation. A final report is then made and a housing report formulated and passed on to the appropriately interested individuals or authorities.

A medical certificate of disability and a housing report are of little value if they fall on deaf ears and unsympathetic minds. The interest and help of the Medical Officer of Health, Welfare Officials and Housing Managers is essential in most cases requiring rehousing or housing alterations. The co-operation and mutual understanding between the Industry, the Unions, the local councils, private landlords and the medico-social worker is vital unless private means are available.

In the past Io years, 70 miners with severe degrees of paralysis have been rehoused while 25 with lesser degrees of disability have had housing alterations. The remainder of the total group of 127 did not require any special housing adjustments.

It is pleasing to report that there has been a considerable improvement not only in the provision of houses for the disabled but their speed of attainment. In the North and Midlands the construction of flats and bungalows for the disabled is still receiving increased consideration by all grades of local authority. In this connection it is also pleasing to record the wide use of a recent publication entitled, Designing for the Disabled, which is a manual of technical information prepared by Selwyn Goldsmith and published by the Royal Institute of British Architects Technical Information Service.

I was recently invited to the official opening of four bungalows for disabled people. The local authority was a small one but they had included these buildings in one of their development programmes and they rehoused four cases with disabilities, a case of multiple sclerosis, an old case of poliomyelitis, a case of rheumatoid arthritis and a case of spinal paraplegia.

We have to appreciate that spinal paraplegia is only one of many disabilities requiring this sort of consideration.

\section{WORK AND INDUSTRIAL RETRAINING}

If the improvement in attention to problems of rehousing can be regarded as encouraging I am afraid that the same cannot be said for the problems of industrial retraining and a return to work.

There were 127 mining accidents in the original instance. Of the 12 cervical cord lesions, neither of the two cases with complete paralysis were fit enough to attempt any retraining but three of the Io cases with incomplete paralysis returned to some form of light work outside the industry. The disability of the remainder was such that I could not expect them to be capable of a remunerative occupation even under the most sheltered of conditions. 
There were five cases of dorsal cord injury; one of these, a young man, returned to work in the colliery offices.

The lower dorsal injuries provided the largest case group of 85 cases of which 25 had incomplete and 60 had complete paralysis of both legs and loss of bladder and bowel control. Five of these found some occupation within the industry.

The lumbar injuries amounted to 25 cases, of whom four found some gainful occupation also within the industry itself.

Thus 13 out of a total of 127 cases attempted and achieved a full working day on a competitive wage. This is Io per cent. of the original group and does not make impressive reading. It obviously requires some correction before it represents a true picture of the state of affairs.

During the Io-year period there were I6 deaths from various causes both related and unrelated to the paraplegia. There were 33 patients who were considered unfit for employment by reason of age and/or physical disability alone. This meant that the potential workers formed a group of 78 cases of whom only 13 actually desired and achieved gainful employment.

Some of the reasons for this low figure are not hard to find. Fifty per cent. of the mineworkers were over the age of 40 and had already spent 20 or more years in the mines. Many were old for their years and were married with teenage children, some of whom made substantial contributions to the household finances. The lack of financial incentive is shown by the benefits available in such cases (tables V and VI).

TABLE V

Financial Benefits (1963)

Unmarried Man

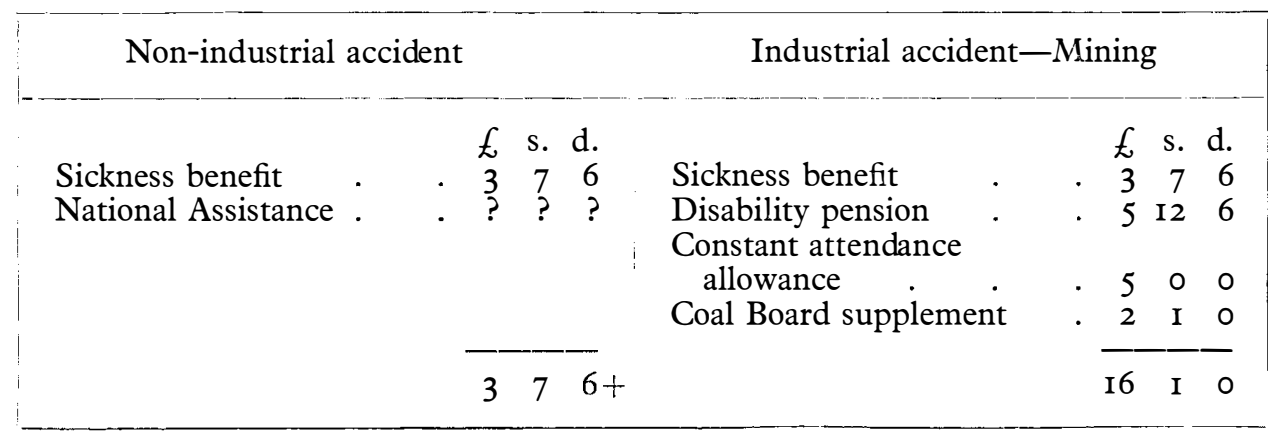

The loss of benefit due to earning capacity is not inconsiderable. Indeed some men would actually suffer financial loss by attempting to work. Other deterrents include the physical difficulties and lack of access to suitable work, coupled with travelling in bad weather, for we must remember that many mining villages are grouped round the colliery and completely remote from other forms of industry.

A high proportion of the non-workers had hobbies and part-time occupational interests with small and undeclared financial reward with the minimum of inconvenience while retaining the full statutory benefits.

And finally, there must be taken into consideration the awards of damages at Common Law which are additional to the disability pension and its supplements. 
I am not discouraged or despondent over the re-employment figures in the mining industry. I take consolation that many men are fit and well and fully occupied with outside interests, including sport. The fact that they do not come on a pay roll is scarcely relevant.

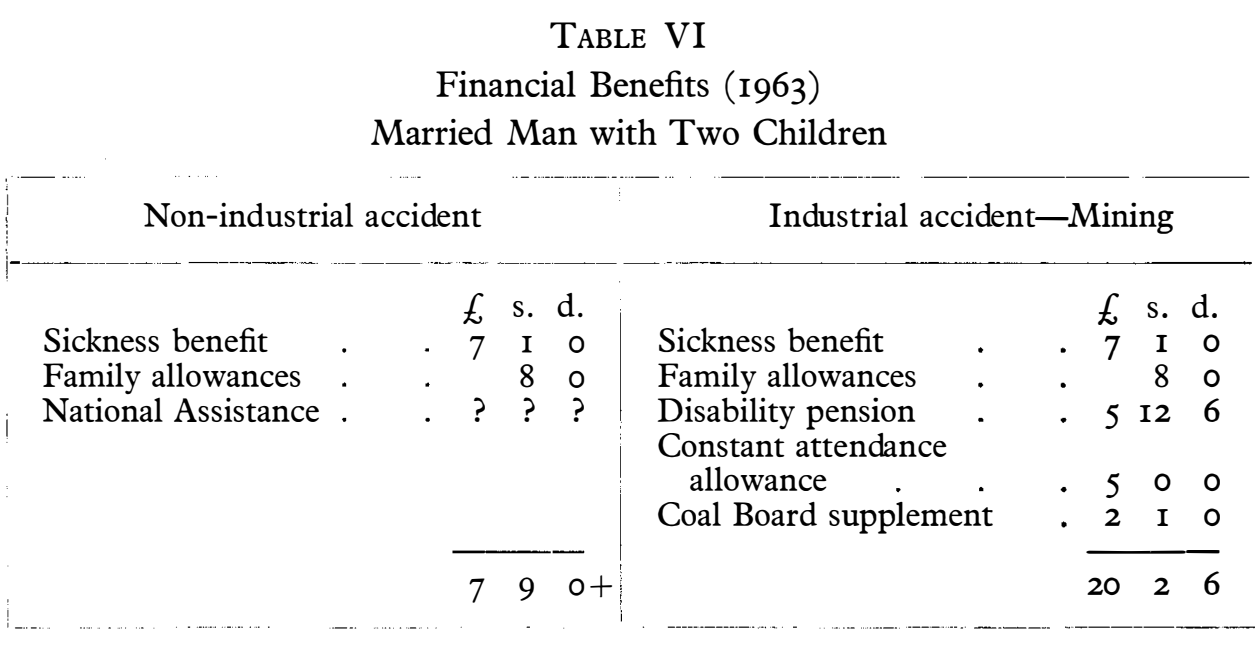

REFERENCE

Nicoll, E. A. (1946). Report to Miners' Welfare Commission.

\section{SOCIAL ASPECTS OF PARAPLEGIC COAL-MINERS IN GERMANY}

By F.-W. MEINECKe, M.D.

Abteilung für Rückenmarksverletzte, Chirurgische Klinik der Berufsgenossenschaftlichen Krankenanstalten 'Bergmannsheil', Bochum, Germany

GERMANY has a system of compulsory insurance. It consists of the following:

Legal Accident Insurance. Every employee is insured against injuries occurring on the way to work, at the place of work or on his way home from work, as well as against diseases acknowledged as occupational diseases. The insurance premium is paid exclusively by the employer. An income limit for this insurance does not exist. It is furnished by the Employers' Liability Insurance Associations.

Health Insurance. It provides for payments (doctor's fees, hospital treatment, medicaments, sick benefit, etc.) for all health damages to the insured or his family that have not occurred during the activities stated above. The insurance premium is paid half by the employer and half by the employee. Office workers with a monthly salary of more than I250,- DM and workers with more than $660,-$ DM monthly income are not included in this insurance scheme. 